\title{
FERNANDO FORTÚN: SU OBRA Y SU PERSONA
}

Todo lector familiarizado con la poesía hispánica moderna reconoce de inmediato el nombre de Fernando Fortún por ser coeditor de la antología La poesía francesa moderna (Madrid, 1913), preparada con el escritor español Enrique Díez-Canedo. Muy leída en la época, esta antología fue aprovechada por los poetas de aquellos años, no siempre bien informados sobre los movimientos literarios en Francia a partir de los parnasianos y los simbolistas. Este volumen, pues, tiene la singular importancia de constituir una fuente para la temprana formación de muchos escritores modernos, especialmente en Hispanoamérica. Cabe recordar que los editores no sólo hicieron sus propias versiones, sino que incluyeron las de otros traductores.

Si todo el mundo conoce los méritos superiores de DíezCanedo, fino crítico y poeta, en cambio poco se sabe de Fernando Fortún (1890-1914), escritor de breve vida y parca obra. Las presentes páginas aspiran a puntualizar unos pocos datos referidos al malogrado poeta, que pasó como relámpago por el mundo literario español durante las primeras décadas del siglo. Sin embargo, a las alturas de hoy la información sobre Fortún es escasa, y su nombre suele faltar en los manuales y diccionarios de la literatura, a menos que se le mencione de paso como uno de los editores de la aludida antología. Tampoco ha tenido mucha suerte en las colecciones poéticas de la época ${ }^{1}$ aunque en tiempos más

1 Al formar en 1906 la antología "oficial" del modernismo (La corte de los poetas, Madrid, 1906) Emilio Carrère no incluye a Fortún; Eduardo de Ory (La musa nueva, Zaragoza, 1908), cuya antología complementa la anterior, recoge un solo poema ("Spes", pp. 70-71), y posteriormente José Brissa (Parnaso español contemporáneo, Barcelona, 1914) y Ramón Segura de la Garmilla (Poetas españoles del siglo xx, Madrid, 1922) incluyen el largo poema "En tierra vasca", uno de los más característicos del poeta recién fallecido hacia aquellos 
recientes han sido incluidos algunos poemas suyos en las de 1; poesía modernista ${ }^{2}$. Como ejemplo típico me permito transcri bir la nota de presentación que hace Federico Carlos Sáinz di Robles, quien recoge en su amplia antología cinco composicione de Fortún:

Poeta y crítico. Sabemos muy poco de su vida. Tradujo, con Díez Canedo, magistralmente, una Antología de poetas franceses con temporáneos. Colaboró con asiduidad en algunas revistas universi tarias. Como lírico poseyó un hondo pensamiento filosófico, un expresión moderna y tersa, gran sensibilidad. Obra: Reliquias $1914^{3}$.

No menos informativas y vagas, por no decir equivocadas, so: las palabras de González Ruano (recoge dos poesías en su antolc gía): "Nació en Madrid. Murió en 1914. Por lo poco que de i conocemos, Fernando Fortún aparece como un poeta bien dota do con pocos contactos con su tiempo y un pensamiento filosóf co. Publicó: Reliquias Madrid, 1914)"'4. En cambio y por otr parte, sería injusto no citar aquí un reciente y bien informado al tículo de Juan Manuel Bonet, cuyo acertado título ("Tras 1 sombra de Fernando Fortún') sugiere por supuesto la evident dificultad que hay para precisar datos sobre el poeta ${ }^{5}$.

años. No figura Fortún en las antologías ya clásicas de Gerardo Diego (193: 1934) y de Federico de Onís (1934).

2 En su Antología de la poesía modernista (Barcelona, 1969) Pedro Gimferr incluye de Fortún cuatro de los "Sonetos románticos" y tres otros poem: (pp. 270-275). Ignacio Prat (Poesía modernista española, Madrid, 1978) reprod ce nueve poemas más unos fragmentos (pp. 200-208). Antonio Fernánd Molina (Antología de la poesía modernista, Madrid, 1982) incorpora cuatro po mas de Fortún (pp. 229-231).

${ }^{3}$ Federico Carlos Sáinz de Robles, Historia y antología de la poesía españ la, Aguilar, Madrid, 1948, pp. 1443.

${ }^{4}$ Cěsar González Ruano, Antología de poetas españoles contemporáneos, Ba celona, 1966, p. 289.

5 Juan Manuel Bonet, “Tras la sombra de Fernando Fortún", Fin Siglo, 1984, núms. 9/10, 41-52. Pěre Gimferrer recoge en su libro Los ral (Barcelona, 1985) una nota "Fernando Fortún, ahora" (pp. 245-247), en cual elogia el artículo de Bonet, opinando que el olvido en que ha caído obra de Fortún se debe a un hecho temporal: su obra fue interrumpida pres samente cuando empezaba a afirmarse un cambio fundamental en la literat ra hispánica. Pregunta luego si Fortún, detenido por la muerte a mitad c camino, hubiera podido superar el ámbito modernista, agregando "no resul sólo conmovedor y pintoresco, sino también en sus piezas máximas, técnic 


\section{Dos obras de Fernando Fortún}

En vida Fortún publicó una sola obra, luego repudiada por su autor: La hora romántica (Madrid, 1907). El libro tiene prólogo de Villaespesa (pp. 7-13), en que se acuerda de su propia adolescencia al comentar la poesía primaveral de su amigo, y advierte en ella el alto grado de intensa subjetividad ("Su poesía es toda alma", p. 12) tan evidente en esos versos del joven poeta, de sensibilidad precoz. Señalada la sobriedad del libro, Villaespesa caracteriza con acierto la poesía de Fortún de la siguiente manera:

...Prefiere el dibujo al color; huye de los tonos agrios, de las notas ásperas, buscando, en cambio, las grandes pausas, los largos silencios, porque en ellos siente mejor el ritmo interno de su alma. Ama las penumbras donde sus ojos, libres de la ceguera de la luz, pueden distinguir y separar los matices más inverosímiles (pp. 12-13).

Poesía intimista, pues, de tono menor, melancólica y rica en sensibilidad. Romanticismo sí, en el sentido más amplio de la palabra, depurado y personal por una parte, y modernismo refrenado o apagado por otra. En una carta de 1910 dirigida a Juan Ramón Jiménez, a quien le había mandado anteriormente un ejemplar de La hora romántica, escribe Fortún el siguiente juicio severo sobre aquel libro suyo que "... fue el hijo de los alborotos y las inocencias de mis diez y seis años, y de cuyo nombre no querría acordarme; procure usted olvidarlo, se lo pido"'6. Más adelante nos ocupará la temprana poesía del libro primigenio de Fernando Fortún.

Póstumamente se publicó otro libro, de tipo misceláneo, en una tirada de doscientos ejemplares no destinados a la venta: $R e$ liquias (Madrid, 1914), cuya pulcra edición fue cuidada por Juan Ramón Jiménez ${ }^{7}$. El volumen consta de varias partes: poesías,

mente admirable" (pp. 246-247). Debido a la gentileza del profesor Nigel Dennis, me ha sido posible consultar la tesis de maestría de Mercedes Roldán presentada en la Universidad de Ottawa (1990) con el título de Fermando Fortún y el modernismo español. La investigación de Mercedes Roldán me resultó muy útil, porque ella recoge algunos datos biográficos de Fortún que no tenía al iniciar el presente trabajo. Para los dos, mis más expresivas gracias.

${ }^{6}$ Fernando Fortún, Reliquias, Madrid, 1914, p. 130. En las presentes páginas se utilizan dos abreviaturas para referirse a las obras de Fortún: $H$ (La hora romántica, Madrid, 1907) y $R$ (Reliquias, Madrid, 1914).

${ }^{7}$ Juan Guerrero Ruiz, Juan Ramón de viva vaz, Madrid, 1961, p. 33. Según Bonet (art. cit., p. 45), Díez-Canedo colaboró en el rescate de los tex- 
1907-1914 (pp. 11-84), escritas después de la publicación de $L$ hora romántica; dos prosas críticas ("Tassara", pp. 87-98 y "Ro drigo Caro y el Capitán Andrade", pp. 99-110) fragmentos y esbozos de poemas no acabados, versos sueltos : notas (pp. 113-120). Cierra el libro un interesante epistolarii (1910-1913) a Juan Ramón, Cipriano de Rivas (Rivas Cherif) Díez-Canedo, así como otras, principalmente las que fueron diri gidas a su madre hacia finales de su vida (pp. 129-171). Segú los encabezados de las cartas, se ve que Fortún estuvo al meno una porción (tres meses) del año de 1910 en París, luego en Gine bra al año siguiente, y en Andalucía (Jerez, Sevilla, Málaga) du rante 1913. En las cartas a su madre elogia calurosamente la ciudades andaluzas, de modo especial a Sevilla ("ciudad dra mática", $R$, p. 166) aunque expresa menos entusiasmo ant Málaga.

Entre las cartas publicadas en Reliquias se incluyen siete de tc no personal enviadas a su amigo Cipriano de Rivas. Son del añ 1910 (cinco escritas en París, dos en Madrid) y quizá la últim sea de febrero del año siguiente. Debido a la falta de testimonic sobre la persona de Fortún (más adelante se transcribe el retrat sutil hecho por Juan Ramón), conviene intentar decir algo sobr la intimidad espiritual del escritor, y las aludidas cartas sirve precisamente para revelar algunos rasgos de su carácter. En u plano informativo Fortún habla desde luego de sus impresione: no enteramente favorables al comienzo, de la capital francesa, de sus diversiones (teatro, exposiciones de arte, nuevas lectura: especialmente de André Gide). Sin embargo, en instantes d acendrado autoanálisis, se refiere Fortún a problemas psíquicc que le afligían. En efecto, durante aquellos meses pasa por un crisis espiritual, experimentando una pronunciada impotenci para hacerse camino en el medio ambiente. En sus momentc neurasténicos, de fastidio y aburrimiento, se siente desorientad, fluctuando entre exaltaciones y abatimientos. Está buscand، pues, un orden y un sentido en las mil cosas que están revuelt: en su conciencia, y por encima de todo quiere escapar hasta c

tos, lo que me parece muy plausible.

${ }^{8}$ Basta decir aquí que en esos textos, que me interesan tan solo de mor tangencial, se utiliza un lenguaje crítico eficaz y expresivo. Fueron escrit aparentemente para un programa ("Florilegio de poetas") organizado por Ateneo de Madrid en 1913. Se trata, pues, de una crítica personal pero bi informada, y de estas páginas se desprende de inmediato que Fortún es m amigo de la emoción que de los preceptos horacianos. 
sí mismo y de la realidad. Agotadas sus fuerzas vitales, repite a menudo su deseo de alejarse de Madrid, de huir y explícitamente de no tener que pasar otro invierno allí, lo que constituiría - dice- un verdadero peligro para su alma y su cuerpo. Y de cuando en cuando una referencia a su ilusionismo amatorio. A mi juicio la carta más significativa en el presente contexto es la de febrero de $1911(\dot{\dot{d}}$ ?), en ella sin vacilaciones habla de su estado de ánimo depresivo y frustrado:

... Desear ... Esta inquietud tremenda de todas mis horas, esta angustia que me ha traído adonde estoy ahora, no tiene otra causa ni otro motivo. La importancia de las cosas no está en las cosas mismas, sino en la vehemencia o en la frialdad de nuestra mirada. Y la mirada nace de la intensidad de nuestro deseo. Toda la enorme tensión espiritual de los judíos - creo que yo tengo gotas de sangre scmita-, que les ha hecho el pueblo más inteligente de la tierra, pero que les ha impedido formar en la tierra un pueblo, creo que nace de lo infinito de su deseo. Un deseo tan devorador, tan potente, que cuando llegó el instante de la realización no les deja creer: han de seguir esperando; el deseo es mejor alimento espiritual que la posesión ( $R$, p. 145).

Antes, en la misma carta, Fortún confiesa que está lejos también la realización de su vago afán artístico, y del proceso creador y las aptitudes poéticas opina:

... Seguramente se puede ser poeta por ardor intelectual, por melancolía, por moral: toda materia es buena con tal que llegue a ser formulada conscientemente; es decir, que en un momento la voluntad artística prevalezca, triunfe sobre la cualidad del sentimiento. Pero aquí está el peligro. Si la pasión es fuerte, la sensualidad ardiente, el ímpetu apostólico sincero, la obra o será tanto más bella, más completa, o no será, por triunfar sobre la voluntad artística el ímpetu, la sensualidad, la pasión que debieron ser la carne y la sangre para la obra (ibid., pp. 144-145).

Está estrechamente unida esa angustia del creador con su propio problema psíquico:

... Es sentirse incompleto, impotente, como es el idéntico desarrollo del proceso artístico en mí: desaforada exaltación liminar, encendida y apasionada génesis - y realización lastimosa cuando la hay, cosa que, como sabes, no ocurre ya hace bastante tiempo. 
¿Causas? De lo primero, en lo artístico seguramente... exceso dt inteligencia, de sentido crítico (ibid., p. 46).

De este modo con un estado psíquico característico de un jover sensible e inteligente a la vez se combina no sólo un afán analíticc sino también una salud siempre precaria.

\section{UNA VIDA INCOMPLETA}

Fernando Fortún nació el 30 de mayo de 1890 en Madrid y mu rió en Las Rozas (Provincia de Madrid) el 6 de mayo de 1914 a consecuencia de tuberculosis pulmonar, antes de cumplir lo veinticuatro años. Terminado el bachillerato en el Instituto $\mathrm{Ge}$ neral y Técnico de San Isidro en 1906, ingresó en la Universidar Central, Sección de Derecho, Facultad de Filosofía y Letras e ini cia sus estudios universitarios en el curso de 1906-1907, comple tándolos tres años después en 1910. Su vida literaria abarca ape nas ocho años: perteneció al grupo numeroso de poetas : bohemios que rodeaban a Villaespesa y seguramente asistía tam bién al salón de Carmen de Burgos (Colombine) hacia los mis mos años. Colaboraba, con verso y prosa, en la Revista Latin (1907-1908) de Villaespesa, en cuyas páginas figuraban todas la importantes firmas del día. Es muy probable que Fortún hay: publicado también en la Revista Crítica (1908-1909), que dirigí: Carmen de Burgos ${ }^{9}$.

Se le menciona de cuando en cuando en las memorias de 1 : época. Felipe Sassone, quien reseña La hora romántica (Revista La tina, marzo de 1907, núm. 6, pp. 49-50), se acuerda de la cas: barata donde vivió Villaespesa y allí conoció a varios escritores inclusive al joven poeta Fortún ${ }^{10}$; Ruiz Contreras, que en aque entonces frecuentaba la casa de Carmen de Burgos, se refiere Fortún como "poeta delicado que murió en la flor de su edad"11 y por su parte Pío Baroja recuerda haberlo conocido en un viaj en carricoche desde Denia a Alicante, agregando "... creí qu sería, como decían entonces, muy modernista; pero al hablar cos

${ }^{9}$ Lo confirma Bonet (art. cit., p. 43) y agrega que también publicó e La Lectura.

${ }^{10}$ Felipe Sassone, La rueda de mi fortuna, Madrid, 1958, pp. 347-348.

${ }^{11}$ Luis Ruiz Contreras, Memorias de un desmemoriado, Madrid, 1961 p. 484 . 
él, vi que era entusiasta, como yo, de Carlos Dickens y de Paul Verlaine" 12 .

De mayor importancia que estas referencias escuetas para la semblanza de Fernando Fortún son los testimonios de tres amigos que influyeron en su vida y orientación literaria: Tomás Morales, Enrique Díez-Canedo y Juan Ramón Jiménez. Desde muy temprano se formó entre el poeta madrileño, levemente menor, y el poeta de la Gran Canaria una entrañable amistad. Morales fue, por supuesto, un poeta de cierta categoría en las postrimerías del modernismo peninsular, combinando resonancias de Darío y Rueda con una predilección por algunos temas más sencillos o menos cosmopolitas (recuerdos sentimentales de la infancia, motivos hogareños y modestos). Se destacó desde un principio como poeta del mar y del puerto de Gran Canaria, y luego abandonó este mar humano y vivido para sumergirse en otra visión más amplia de un mar mitológico expresada en sonoros versos de largo aliento, de corte clásico ${ }^{13}$. Morales es, pues, un poeta elocuente en el mejor sentido de la palabra, autor de odas escritas en versos recios y resonantes, y la poesía más delicada de su juventud parece ceder ante el empuje de los versos de tono mayor que caracterizan su plenitud.

Fortún publica un largo comentario sobre el primer libro de su amigo (España Nueva, 26 de junio de 1908, núm. 775). En Poemas de la gloria, del amor y del mar elogia la original y fuerte personalidad de Morales, y considera la parte más novedosa e intensa del libro los poemas inspirados en el mar y el puerto, mundo no explorado en la nueva poesía española. Fortún, después de haber señalado el parentesco entre Morales y Tristán Corbière, otro hijo del Atlántico, niega que sea parnasiano aunque en algunos sonetos pudo parecer discípulo de Heredia, y " . . c canta el mar con un amor filial y romántico que ha cristalizado en una hermosísima poesía, luminosa, magnífica e impecable, de las más bellas

12 Pío Baroja, Desde la última vuelta del camino, Barcelona, 1970, t. 1, p. 655 .

13 Enrigue Díez-Canedo, "Tomás Morales", en Estudios de poesía española contemporánea, J. Mortiz, México, 1965, pp. 192-193. Sobre el poeta canario es de indispensable consulta la excelente obra de SEBASTIÁN DE LA NUEZ, Tomás Morales: su vida, su tiempo y su obra, 2 ts., Universidad de La Laguna, 1956. Reproduce también (t. 1, p. 209) una interesante carta de Fortún, escrita hacia 1911, a su amigo en que ironiza sobre el teatro de Villaespesa y habla de otras actualidades literarias del día. Véase además t. 1, pp. 95-97 y 113-116. 
que ha producido la lírica española contemporánea'. Mencior la perfección formal de sus admirables sonetos (el molde prefer do de Fortún), y no deja de advertir la pureza lírica de las rim: sentimentales, "que suenan como un llanto de una fuente en crepúsculo". Con esa melancolía romántica de los recuerdos con una poesía del pasado pueden identificarse ambos poetas $\mathrm{c}$ mo luego veremos. Con brevedad se ocupa de los "poemas c la gloria", algunos de acento madrigalesco y un aire de sensual dad modernista. Constituyen, a pesar de su belleza rítmica, parte menos original del libro según Fortún.

Tomás Morales dedica el poema VI de la sección "Vac ciones sentimentales" a Fernando Fortún (su título original $\epsilon$ la Revista Latina: "A Fernando Fortún, poeta"), y comien: con dos versos sugestivos para establecer la herencia de ambı poetas:

Esta tarde he leído a Rodenbach. El día

ha sido el más propicio que hubo en todo el Verano...

Dirigiéndose directamente a su amigo y llamándole por su nor bre, confiesa que ha encontrado en el silencio de esta tarde el c ma de los salones y los muebles ("Les chambres, qu'on croirc d'inanimés décors'). El poema sigue la pauta intimista del poe belga de Les vies encloses y Le règne de silence, es decir el obje Ło c sí constituye un punto de partida para engendrar todo un aire rico, e identificándose con él, el poeta revela en el acto conter plativo la parte más íntima de su propia alma. Se sutiliza el esf ritu del poeta y se vuelve a citar a Rodenbach: " Douceur du soi Douceur de la chambre sans lampe". Ha llegado el instante $\mathrm{m}$ gico: en medio del silencio y la oscuridad, el poeta se disuelve sus sueños y se interna en el misterio de las cosas mientras ava zan las sombras del crepúsculo. De repente se oye un repique . campanas; en los muebles del salón, antes silenciosos, se efectú: cambios sensibles; y la campana ha preludiado la llegada de 1 viejo criado que enciende la lámpara. Se rompe, pues, el sorti' gio: las sombras se vencen y se esconden. Al final el poeta asom do a la ventana contempla la paz del campo crepuscular y dic "Pensé unos versos tuyos: Parece que mi alma / salió de mi, y se hecho el alma de este ocaso..."

En 1914, profundamente herido por la muerte prematura su constante amigo, Morales escribe un hermoso y sentido car elegíaco ("En la muerte de Fernando Fortún"), en el cual 
menta con evidente sinceridad su fallecimiento temprano e inesperado, ocurrido en plena juventud. Ante lo ineludible de la muerte, el poeta ha quedado solo y abatido, expresando de la siguiente manera el alcance de su amistad y el dolor de la pérdida:

Tu superior hombría

dio a mi amistad hospitalario abrigo:

¡feliz yo, que podía,

al platicar contigo,

llamarte, en toda su hermosura, Amigo!

No oír ya más tu verbo,

tu amada voz que cercenó el agravio

de algún hado protervo!

¡No escuchar más el sabio

don, sosegado y noble, de tu labio!

La bondad de Fortún asegura paz y armonía para su obra; se desarrolla en varias estrofas la imagen del vaso roto, cuyo contenido líquido se derramó conviertiéndose en giros de luz; y la poesía del muerto le va a sobrevivir, alcanzando una duradera gloria, tranquila y sin honores, pero ampliamente reconocida por sus hermanos los poetas. En las estrofas finales de la elegía se expresa la inevitabilidad del último viaje ${ }^{14}$ :

Emplazados nos tiene

y huir su encuentro es ilusión villana:

nadie su amor previene,

la juzgamos lejana,

y a nucstro lado está. Tal vez mañana...

Una cita tenemos

que es blanca luz en medio de mi espanto:

¡moriré y nos veremos!

No secará entre tanto

la vena dolorida de mi llanto...

${ }^{14}$ Con motivo de la muerte del joven poeta, también VilLAESPESA entona su doliente elegía, insistiendo en la tierna edad del desaparecido, que quedó tan sólo en la promesa de realizarse más plenamente. Pide a los poetas que salven del olvido el nombre de Fortún, de espíritu puro y alma romántica, y acaba suplicando a Dios que dé al joven en la otra vida lo que le negó en ésta. La elegía pertenece al libro Campanas pascuales (1914) y se reproduce en Poesias completas, Aguilar, Madrid, 1954, t. 2, pp. 174-177. 
Otro gran amigo de Fortún, con quien colaboraba en la Anto logía de 1913, fue desde luego Díez-Canedo, crítico y poeta de in mensa cultura. Sin duda influyó en el joven escritor. Al prologa en 1922 el primer libro de Las rosas de Hércules de Morales, n puede menos que recordar el afecto entrañable que los unía, es aquel entonces muertos los dos:

... los dos eran como esos compañeros de armas que en los viejc cantares de gesta aparecen unidos por una suerte común y llame dos a igual destino.

... Empezó su amistad cuando se decidía la vocación literaria d ambos y se lanzaban por el camino en que su compañero, mayc en edad, le llevaba escasa delantera. Era Fernando más íntimo reconcentrado. Tomás, impetuoso, cantaba en notas más alta: Uno y otro seguían, vagamente, los estudios universitarios ${ }^{15}$.

En la última edición aumentada y con el título levemente can biado de la Antología se refiere Díez-Canedo a su antiguo eolabc rador en los siguientes términos:

... Su preciosa ayuda hizo posible no solamente el gran acopio c datos allí ofrecidos sino su coordinación, que apenas podía yo ater der desde París, en donde me hallaba cuando pusimos manos a obra. Sí pude, ya de regreso en España, cuidar de la impresiós siempre con el asiduo trabajo de Fernando Fortún, de quien erar además, muchas de las versiones más felices, entonces realizadi expresamente para el libro ${ }^{16}$.

En efecto la labor de Fortún como traductor no era poca: tradu a dieciséis poetas, con un buen número de poemas en más c un caso. Además muchas noticias biobibliográficas se debían $\mathrm{s}$ guramente a él. Por supuesto antes de la publicación de tan afo tunada antología los dos editores se habían conocido, y por ur carta de $1910(R$, p. 139) se sabe que estuvieron juntos en Par por algún tiempo. También en otra carta, ahora de $1911(R$, 148) anuncia a Díez-Canedo su deseo de estudiar filología cc Menéndez Pidal. Si no logra avanzar en esta disciplina, dice, i: a París para entrar después en el cuerpo diplomático. De Cád (4 de octubre de 1913) se conservan algunas líneas enviadas

${ }^{15}$ Dímz-Canedo, op. cit., pp. 189-190.

${ }^{16}$ DíEz-CANedo, "Advertencia preliminar", La poesía francesa del roman cismo al superrealismo, Buenos Aires, 1945, p. 5. 
mismo, en las cuales habla de sus diversiones, entre artísticas y toreras, durante su estancia en Andalucía: Zurbarán y Belmonte, Murillo y El Gallo ( $R$, p. 161). Díez-Ganedo siempre demostró fidelidad a la amistad que le unía con su malogrado amigo, y en 1924 escribió “ “. . fué más amigo mío que lo ha sido nadie en el mundo... Nadie conoce acaso como yo la lucidez de su juicio, la seguridad de su gusto" 17 .

Las relaciones amistosas mantenidas con Juan Ramón Jiménez, con quien se pone en contacto a través de su amistad con Díez-Canedo, constituyen una importante fuente de apoyo literario como era el caso de tantos otros poetas jóvenes que iniciaban su obra hacia aquella época. Fortún admiraba mucho al poeta de Moguer, centro de gran parte de la actividad poética aunque vivía retirado de la vida literaria de Madrid. Al acusarle recibo de Poemas mágicos y dolientes, Fortún escribe en 1912 al autor del libro el siguiente elogio ${ }^{18}$ :

... Pero hablar de sus libros, cada vez más puros, más inefables, más divinos, es algo que no puedo intentar. Tan cercanos están de mi corazón, tan fuertemente se apoderan de mí, que olvido son las más puras manifestaciones de belleza, los más altos ejemplos de arte; del nuestro actual, para considerarlos como algo natural y divino, como la primavera con rosas, como el otoño con oro... escribir a usted después de la lectura de un libro suyo, es para mí como si hubiera de escribir a Heine, a Musset, a Verlaine, a Guérin... (R, p. 159).

$\mathrm{Al}$ menos en dos ocasiones Fortún consultó al poeta andaluz sobre la formación de una antología de poetas modernos españoles, que piensa editar con Ángel Vegue y Goldoni, obra que nunca llegó a publicarse. Parece que el único americano que se iba a incluir era el indispensable Darío, y quizá se hiciese la excepción de Icaza porque se había hecho poeta en Madrid. Unos meses después (septiembre de 1910) vuelve a hablar de la proyectada antología en una carta a Jiménez: ahora los editores han cambiado de idea y piensan hacer un florilegio selecto y riguroso. En el mismo lugar ( $R$, pp. 140-141) Fortún señala los títulos de

17 Bonet, art. cit., p. 43.

${ }^{18}$ En otra carta anterior (1910) se refiere Fortún en altos términos de elogio a la emocionada e intensa impresión que ha producido en él la lectura de Elegias lamentables, obra leída en horas de enfermedad y crisis espiritual (R, p. 147) 
poemas de Juan Ramón que quiere incluir desde Rimas hasta lí obras más recientes, y declara que lo apartado de Juan Ramór Darío, Antonio Machado y Marquina llenaría el volumen ${ }^{1}$ Por su parte, Juan Ramón no sólo cuida desinteresadamente ] edición póstuma de Reliquias, sino que también hace un retrat de Fortún que no figura en la primera edición de Españoles de tr mundos (Buenos Aires, 1942). El texto inconcluso se recoge e ediciones posteriores y de él transcribo, con cierta extensión, a gunos fragmentos que definen el modo de ser del joven poeta

En nuestro pequeño grupo espartano ordenado por una amisté apolínea, pura, pero sin aquella sequedad ascética con que aspir ba a la efímera e inútil (y vana) corona de perejil, tú, Fernand eras el más joven y quizás el más dulce. Llegabas sonriente y af ble, adornado de buenas maneras, y dabas la mano con una bla dura leve y efusiva. Parecías un Chopin adolescente y elegant fresco y mustio a un tiempo; tu sonreír mustio y caído revolal alrededor de todo tu rostro como una pálida mariposa amable; $r$ vuela alrededor de ese rostro inefable de la mujer tísica de Goy un poco ajado todo tú, me parecías un joven ciprés abatido lev mente por yo no sé qué viento.

Algo mundano y lijeramente indolente, como si tuvieras per za de dejar de oír un solo instante, para cantarla, la música s nombre que oías fluir en los románticos jardines de tu imajinacic a las fuentes del prado único... ${ }^{20}$

\section{Breve aproximación a la poesía de Fortún}

En 1906 se publicó en Madrid una curiosa y desconcertante a tología con el título de La corte de los poetas, editada por el poe bohemio Emilio Carrére, cuyo prólogo agresivo atacaba a 1 académicos y el convencionalismo de los poetas viejos. Esa ant logía aspiraba a representar la juventud, desde Darío para abaj $y$, a pesar de sus grandes defectos y contenido heterogéneo, e la respuesta modernista a sus detractores. Un par de años de pués, en 1908, apareció otra antología titulada La musa nueva, c denada por Eduardo de Ory, quien afirma que hay también ot

19 Por una carta de Fortún a Alonso Quesada, se sabe que en 1913 pє saba editar, con Canedo y Salinas, otra antología "seria y severa". BoNI art. cit., p. 44.

20 Juan Ramón Jiménez, Españoles de tres mundos, Aguilar, Madrid, $19 t$ pp. 289-290. 
núcleo de poetas en España, no de la corte sino de la provincia, todos ellos excluidos de la obra anterior. Estos poetas jóvenes, según el prologuista, escriben con mayor naturalidad y menos amaneramiento, atentos a la expresión de las sensaciones del alma. Esta segunda antología de transición, pues, constituye ya una palpable reacción ante el exotismo de un modernismo exagerado e inútil, optando los escritores por una poesía más cerca de la vida que del arte, rasgo característico del llamado postmodernismo en ambos lados del Atlántico. (Entre paréntesis, el editor incluye de Fortún la composición "Spes".) Fernando Fortún vive esos años intermedios, es decir, entre los últimos rescoldos del modernismo y las primeras obras de los precursores de la Generación de 1927. Así es que nace a la vida literaria en la época de las postrimerías de un modernismo agonizante, en vías de ser superado en sus aspectos más exteriores cuando se iniciaba una concepción estética tal vez más humana e íntima. Otro hecho capital: los mayores poetas y maestros de los primeros años del siglo, Juan Ramón Jiménez y Antonio Machado, ya para estas fechas se habían distanciado del modernismo para crear sus propias personalidades. Desde luego, ese modernismo diluido se desenvuelve a menudo en una poesía de provincia, dirección evidente, por ejemplo, en el realismo sentimental de Andrés González Blanco, cuyos Poemas de provincia (1910) tuvieron ampia difusión tanto en España como en Hispanoamérica aun antes de ser recogidos en libro. En Fortún considero profundo el influjo, entre irónico y sentimental, de Jules Laforgue ("Laforgue: Pierrot entre el barro del miércoles de ceniza", $R$, p. 123), porque ambos deseaban eliminar la solemnidad y elocuencia de la poesía mediante una visión más cotidiana de la vida. Ademas, al leer a Fortún, es difícil no pensar en la poesía suave y recatada de Rodenbach y Francis Jammes.

Decir que La hora romántica es una obra juvenil, a veces ingenua, no puede ser motivo de sorpresa, porque Fortún tenía diecisiete años cuando se publicó. Muy distinta es su poesía posterior aunque en el primer libro comienza, poco a poco, a encontrar un tono propio y personal. Dado el título de la obra, se espera, por supuesto, un fondo romántico de melancolía y desconsuelo, pero no es excesiva la expresión de esa tristeza íntima: se rehuye lo estridente y lo áspero. Más bien el poeta parece resignarse, con actitud serena, ante el dolor del sufrimiento y la frustración de sus ilusiones. Su vida, de jornadas grises y días opacos, pasa aparentemente sin grandes sacudimientos, y hasta anhela una existencia menos ordinaria y más tumultuosa ("Así será...", II). No ha 
encontrado tampoco los amores sublimes y solamente siente u amor sin amar ("Heroica"). Por momentos, Fortún demuestı una fascinación por lo viejo ("El ventanal destruido"), preocr pación que se intensifica después.

Sin embargo, ya se define Fortún desde un principio com poeta del silencio y de todo lo callado, evocando también lo que : acaba y lo que se muere mansamente. Es, pues, en la sección "I triunfo del silencio" (pp. 65-82), con dedicatoria a Juan Ramór cuando empieza a oírse el timbre auténtico de su voz poétic:

En la tristeza del jardín silente sólo murmura la callada fuente su tenue y melancólica canción... El crepúsculo trae a las ventanas los ayes de unas voces muy lejanas que hacen llorar de pena al corazón.

No obstante, otras voces se perciben fácilmente en los versc transcritos. También hay en otra parte del libro una serie de po mas claramente derivados y poco originales, cuya filiación mı dernista es obvia ("Visiones galantes", pp. 38-63). El poeta 1 hecho una concesión a una modalidad poética ya preteritada peligrosa, recreando las fiestas galantes, en salones lujosos o ja dines poblados de esculturas, en los cuales, al son de músicas al das, se mueven mujeres aristocráticas o malignas. En esta poes versallesca hay desde luego voces armoniosas, risas argentinas hasta una princesa rubia "de ojos de Ticiano" y "labios de fr sa" ("Valses"). Abundan las reminiscencias culturales y de m. do especial de las artes plásticas, y que valgan como muestra c esta poesía superficial, pronto abandonada para siempre $\mathrm{p}$ Fortún, los siguientes versos:

Finas voces de plata sonetos de Aretino musitan armoniosas, prometiendo al sonar voluptuosas, vagas, un galardón divino para aquel que tuviera la dicha de triunfar.

Porque eran unas justas de amor y poesía; se recitaban versos al son de un bandolín; y la luz de la fiesta, sus risas, su alegría por abiertos vitrales llegaban al jardín.

("El triunfo del bufón") 
Según Villaespesa (prólogo, p. 13) lo más bello de La hora romántica se encuentra en la sección "Recuerdos de infancia", en la cual se impone por supuesto la visión de un pasado vivido íntimamente:

Opacos días grises de mi infancia, lejanos os remembro en instantes de hastío y de pereza, y llorando de tedio veo que sois hermanos de estos otros que pasan con la misma tristeza.

Apagados recuerdos... No sufro más dolores que el dolor infinito de soportar la vida monótona y silente, guardando los amores divinos hasta el último día de la partida.

Lo que tiende a borrarse y esfumarse en la lejanía se revive, momentáneamente, gracias al don de la memoria, con una nueva intensidad en el presente para luego perderse una vez más en el fluir del tiempo (V). Al contemplarse Fortún pregunta al espejo quién es, al mismo tiempo que insiste en la lejanía de los recuerdos infantiles, y quiere "saber, si siendo un viejo hay en mí un niño, / o siendo aún un niño, hay en mí un viejo"' (I). En delicado soneto emotivo ("La caja de juguetes") pasa revista al contenido de la caja, y, entre los juguetes recordados de aquel tiempo, el último: "una muñeca rota y lastimera, cuya dueña gentil fue la primera / por quien latió mi pobre corazón". Por fin la poesía "Spes", de verso menor, resume el resignado romanticismo de Fernando Fortún, y traza a la vez la trayectoria vital del joven escritor, solo y callado. Sus esperanzas mueren como los reflejos de las llamas del fuego; se llena el alma de miedo ignoto; y piensa el poeta en la infinita soledad de la noche mientras espera lo que no llegará jamás.

Formal y temáticamente Fortún ha pagado inevitable tributo al modernismo de la época (los sonetos alejandrinos, los motivos de los viejos parques y lo versallesco) y no puede ser de otra manera. Por otra parte, La hora romántica es un delicado libro sin asperezas y de clara filiación simbolista que anticipa sin duda algunos logros definitivos de años posteriores.

Las poesías de Fortún coleccionadas por sus amigos en Reliquias (pp. 11-84) se escribieron entre 1907 y 1913, completando, junto con el volumen anterior, la exigua obra en verso del escri- 
tor. Algunas de las composiciones de la última etapa aseguran : Fortún un lugar decoroso en la lírica moderna peninsular. Poe sía, pues, que merecería ser más conocida. Se trata en fin de ui poeta más maduro que ve ahora los temas románticos con ojo crí tico, a veces con ironía y con cierta ambigüedad, todo lo que con fiere una nota más moderna a sus últimos versos. Poesía tambié más exacta y más objetiva, en que tiende a matizar la expresió: de la sensibilidad de antaño. Dicho de otra manera, Fortún y no se abandona totalmente a la emoción, sino que la domina no ella a él. Predominan, a mi juicio, en estos poemas finales do vertientes fundamentales: una temporal (un pasado revivido) otra espacial (la aldea y vida de provincia).

El pasado evocado por el poeta suele ser ahora el de las pr: meras décadas del siglo anterior. Ese pasado decimonónico, ev: dentemente romántico, es más glorioso y más bello que el pre sente actual de cuidados pequeños o hechos banales. Lo mé singular, es que el poeta se instala directamente en lo de antañ para realmente vivirlo y no sólo recrearlo. En "El viejo café", poeta evoca a los tipos novelescos de antaño, conspiradores y r volucionarios fogosos, que decían sus discursos y versos byronic nos, pero finalmente se anula ese aire heroico y de repente s vuelve a la trivialidad burguesa de la vida ordinaria de hoy. I poeta cree verlos todavía sentados a las mesas del café “ . . . dor de se escucha ahora / el sosegado hablar de estas gentes burgur sas / y en el piano, el sueño de un triste vals que llora..." Otr ejemplo del mismo tipo de superposición temporal: "Estos hon bres astrosos..." Así los tópicos románticos que una vez fuero bellos se desvalorizan. En otra poesía Fortún describe el encant de ciertos trozos de las óperas antiguas, ahora cursis y pasadas c moda, que las muchachas cantaban con sentimiento y emoció Y ante la partitura romántica, colocada todavía en el atril, se e: clama: " . . ante ti pasa toda / la historia de aquel dulce amc estudiantil... ¡oh, aquella niña cursi que creí mi ideal!"' (“Pa tituras románticas').

Fortún recrea también aquellos viejos salones y sus secreto adornados de retratos y espejos, así como a los hidalgos qu habían combatido en las guerras carlistas y también a los dand afrancesados ("de melenas nevadas y próceres maneras") que $\bar{l}_{\text {i }}$ mentan el presente antes de quedarse dormidos en sus sillone Habla con clara nostalgia de las miniaturas y de los abanicos, li porcelanas y los tapices, así como de las mujeres con sus vestid, de cola y tocados antiguos. Y hasta pregunta a las damas cordi 
les y coquetas ("con las almas de fuego en un cuerpo de nieve") “¿por qué esa época vuestra no habrá sido la mía?" ("Sonetos románticos", I). A otro soneto de la misma serie (VI) pertenecen estos versos finales que dan una dimensión tal vez menos solemne a los cuadros de las damas románticas del xIx: "Por vosotras, románticas, aun mi corazón arde; / a este mundo tan viejo, he venido muy tarde; / debí ser vuestro amante y he sido vuestro hijo". En la mayoría de los casos se trata de un pasado de esplendor, con que se identifica el poeta, instalándose en aquellos tiempos y compartiendo con las gentes de entonces sus pequeños dramas. También en el poema "En el silencio de la biblioteca..." se combina con su amor por todo lo viejo esa misma doble dimensión temporal mientras lee en la biblioteca municipal, rodeado de los tomos polvorientos que hablan de otras vidas y otras épocas.

Son varios los poemas de Fortún agrupados en las secciones "Notas provincianas" (pp. 39-53) y "En la paz campesina" (pp. 54-70), en los cuales describe la tranquilidad y quietud de la vida de provincia, siempre igual e invariable. Poco o nada rompe el idilio eglógico del campo y la existencia apacible de sus habitantes. El poeta pinta ese mundo cerrado y rutinario de los curas de aldea, de las niñas que en el balcón visten a sus muñecos y de los labradores que a la noche regresan a sus hogares. Como en toda poesía de provincia se oyen esquilas y campanas; se celebran paseos dominicales seguidos por meriendas campestres. Todo huele a paz y a limpieza. La siguiente estrofa es característica de la tonalidad tranquila de esta poesía, que está además siempre atenta a las percepciones sensoriales:

Todo el campo es un dulce olor de membrana, que aroma santamente el silencio aldeano. El ocaso de oro entra por mi ventana con el sereno ritmo de un verso virgiliano.

("Todo el campo...")

Los versos que ahora se transcriben son típicos por el estilo nominal, de fuente impresionista, pero sobre todo interesan porque en ellos se ve cómo el espíritu del poeta y la naturaleza se funden en estrecha unión:

Juegos de niños, lejos... Magnolias. . Paz. . . Olvido

Como el balcón en donde a soñar he venido, 
mi alma, a la tarde, está de par en par abierta.

$\mathrm{Y}$ entra, en el claro torrente de pureza y frescura, siendo agua azul y limpia, el ocaso de seda que, como un manso arroyo, dentro de mí murmura, y en mi alma, que es su cauce, tranquilamente rueda.

("Campanas vesperales")

En otro poema Fortún describe la llegada estrepitosa de la dili gencia e insiste en cómo todo se repite, sin cambio y con ritm igual, e ida la diligencia a la tristeza de la tarde vuelve la calm de antes. Cuando los viajeros desconocidos, grises y opacas su siluetas, descienden del coche recuerdan al poeta unos daguerrot: pos borrosos. Quisiera llamar la atención sobre esta imagen porqu Fortún tiene una predilección especial por todo lo pictórico. E: efecto, una sección de sus poesías en Reliquias se titula precisa mente "Cromos" (la designación es suya y no de los editores) con insistencia notable recurre en sus modos de decir a represer taciones pictóricas: oleografía, cuadro viejo, grabado, antigua estampc retablo. Otros ejemplos del mismo procedimiento:

Las figuras ingenuas que rodean la mesa forman un interior de la escuela holandesa:

("Es mediodía”)

Amo, en silencio siempre, una imagen angélica en un viejo retablo de un pintor primitivo...

("Idilios")

y una expresión broncínea, adusta, dura y fiera, cual las antiguas mártires pintadas por Ribera.

("Las viejas serranas")

una mancha polícroma bajo una sombra amena, perturbando el severo paisaje velazqueño...

("Cromos", III)

Es un enjuto hidalgo acartonado y seco; parece su cabeza una que pintó el Greco,

("En tierra vasca", II)

Y tampoco faltan las referencias literarias: Rabelais, Scarror Musset, Espronceda, Zorrilla y varias otras. 
El largo poema "En tierra vasca", dividido en siete partes desiguales y publicado en 1907 en la Revista Latina, fue favorecido al menos por dos antólogos tempranos de la poesía española moderna (José Brissa y Segura de la Garmilla). Sin duda alguna el poema ofrece momentos muy valiosos y a la vez representa algunas de las cualidades típicas de la poesía de Fortún. Él siente la tristeza y la vejez de la villa de Hernani ("en donde crece el musgo de la melancolía", I). Un día era grande el pueblo pero ahora es solamente " ... una sombra / envejecida y triste como el alma española" (I). En el ambiente, la humedad y la incesante lluvia, y el poeta encuentra un símbolo del dolor de vivir en la hiedra que cubre la piedra:

Sobre la renegrida vetustez de la piedra, crece, como el dolor de la vida, la hiedra.

Y es su verdor más triste que lo gris del granito.

Tiene el lejano encanto doliente e infinito del alma que está enferma por la melancolía...

Y la hiedra recubre también el alma mía, que el dolor, la tristeza, las muertas ilusiones, han hecho ya tan vieja como estos caserones que tienen como arrugas de un rostro envejecido...

En cambio, un día de primavera trae todavía una nota de esperanza: gratos son los perfumes a menta y mejorana que aspiraba de niño, un cielo de cristal ha triunfado sobre la bruma invernal, y se oyen repiques alegres aquel día abrileño. El sol llega también a los caserones pueblerinos:

Y las viejas mansiones, obscuras y musgosas, se diría que al sol se encuentran temerosas, apiñándose en masas adustas y sombrías ante esta luz que no es la de todos los días.

Fragancias, luces tamizadas, sonidos o silencios se perciben en la calma de aquella villa muerta, y el poeta por momentos parece perder su inquietud, entregándose a sus ensueños de una virgen rubia que nunca le ha querido (VI).

Algunas composiciones incluidas en Reliquias son de tipo diferente y por tanto merecen señalarse en apretada síntesis ahora que me acerco al término de estas notas. Un evidente ejemplo: 
el soneto endecasílabo "Tarde madrileña" se inspira en el bullicic y movimiento de algún domingo en la capital, u otro que evoč una noche de verbena ("Cromos", V). Otras poesías, en versc menor, traen eco de las formas populares ("Canción de ronda" "Canción de camino", etc.), y en "Las viejas serranas" se pun tualiza la dura existencia de las segovianas agotadas por el traba jo diario. Por último “¿Qué buscas en los libros...?”, de tonc filosófico, sugiere que los libros pueden constituir una fuente d consuelo para que el hombre alivie su pena y soledad en un mun do inhóspito. Para enriquecer la vida y hacerla florecer, el hom bre, perdido y solo, busca en los libros algo que lo sustente el su calvario y algo con que pueda identificarse plenamente.

El destino no permitió que Fernando Fortún se realizara en teramente, pero sí es autor de algunos buenos poemas, de acentr personal, que le merecen un lugar respetable en la poesía españo la entre las postrimerías del modernismo y los primeros brotes d la poesía contemporánea. Quizá va un poco más Gimferrer eı su acertada valoración de la lírica de Fortún cuando afirma “... llegó a escribir ese indispensable puñado de poemas incon fundibles, que todo poeta necesita para no desdibujarse, para nı ser sólo un nombre más sino precisamente el autor de estas pie zas y no de otras cualesquiera"'21. Siempre atento al simbolismı y a la obra de sus pequeños maestros (Laforgue, Rodenbach, Sa main, Jammes), escribía una poesía delicada y esencialmente lí rica, y se define, en sus mejores momentos, como poeta del pasa do y amante de todo lo viejo. Su vaga melancolía nos habla d cosas que nos entristecen y que nos gustan al mismo tiempc Nunca estridente, cultiva los silencios sugestivos y llenos de ine fable emoción. Escribe de cosas grises y humildes, de temas motivos de la niñez, y cobran nueva vida en su poesía los peque ños objetos familiares de todos los días. Y así Fernando Fortún tierno e irónico, se acerca a la vida interior de las cosas, logrand unos instantes de auténtico lirismo personal.

Allen W. Phillil

University of California, Santa Barbal

Emeritr

${ }^{21}$ GlMfERrer, "Fernando Fortún, ahora", p. 240. 